REVISED

1 Influence of insemination time on the fertility of sex sorted frozen-thawed Y-sperm

2

3

4 Luis Anel-López ${ }^{1}$; Olga Garcia-Álvarez²; Tatiana Tarantini ${ }^{4}$; David Del Olmo ${ }^{4}$ Jose 5

\section{in red deer}

$$
\begin{aligned}
& \text { Antonio Ortiz } ; \text { Sergio Ledda }{ }^{6} \text {, Emilio Arsenio Martinez }{ }^{4} \text {; Ana J. Soler }{ }^{3} \text {; Jordi Roca } \\
& \text { María R. Fernández Santos }{ }^{3} \text {; Juan Maria Vázquez } \text {; Inmaculada Parrilla }{ }^{4} \text {; Jose Julián } \\
& \qquad \text { Garde }^{3}
\end{aligned}
$$

${ }^{1}$ ITRA-ULE, Departamento de Medicina, Cirugía y Anatomía Veterinaria, University of León. ${ }^{2}$ Biomedical Center, School of Medicine in Pilsen, Charles University in Prague, alej Svobody 1655/76, 32300 Pilsen, Czech Republic; ${ }^{3}$ SaBio IREC (CSIC-UCLMJCCM), Albacete, Spain; ${ }^{4}$ Department of Animal Medicine and Surgery, University of Murcia, Murcia, Spain; ${ }^{5}$ Medianilla S.L. Finca Las Lomas, Vejer de la Frontera, Cádiz, Spain; ${ }^{6}$ Dipartamento di Medicina Veterinaria, Universita degli Studi di Sassari.

Corresponding author: Jose Julián Garde López-Brea.

E-mail: Julian.Garde@uclm.es

Full Postal address: José Julián Garde López-Brea

Vicerrector de Investigación y Política Científica

Universidad de Castilla-La Mancha

Edificio José Prat Plaza de la Universidad, 2 | 02071 Albacete

Phone \#: 967599200 | Ext: 2020 |

23

Short Title: Insemination time with sexed sperm in red deer. 


\section{Abstract}

The aim of this study was to assess the effect of insemination timing on pregnancy rates in red deer (Cervus elaphus) when using sex-sorted sperm samples. Semen was collected by electroejaculation from 8 mature stags and processed to obtain: Conventional samples, following standard freezing procedures for commercial purposes; Control sorted samples, diluted and handled as per sorted samples but without being submitted to the sorter passage; and Y Sex Sorted (YSS) samples. Hinds were synchronized via intravaginal CIDR (Controlled Internal Drug Release) placement and given eCG (Folligon ${ }^{\circledR}$ PMSG Serum Gonadotrophin) on day 12, upon CIDR removal. They were then inseminated with one of each sperm treatment, at the following post-eCG intervals: I_1, 55:01 - 55:30 h; I_2, 55:31 - 56:00 h; I_3, 56:01 - 56:30 h; or, I_4, 56:31 - 57:00 h. Pregnancy rates were assessed at parturition. Average pregnancy rates were highest $(\mathrm{P}<0.05)$ for Conventional samples $(77.6 \%)$, but similar between YSS (49.8\%) and Control sorted (51.3\%) samples. However, when insemination interval was taken into account, pregnancy rates within the YSS group, pregnancy rates were 80 and $83.1 \%$ for I_1 and I_2, respectively were obtaioned. Notably, these rates were similar $(\mathrm{P}>0.05)$ to the average pregnancy rates obtained with Conventional samples (77.6\%). As expected, YSS sperm yielded 94\% male offspring contrasting with the 57\% males obtained with Conventional and Control sorted samples. Our findings support the importance of developing specific insemination timing protocols to improve pregnancy rates when using frozen-thawed sex-sorted sperm. These findings provide the foundation for further investigations in order to determine why the YSS sperm are able to fertilize the oocyte in a shorter period of time than the conventional samples.

Key words: Red deer; Artificial insemination; Sex-sorted sperm; Insemination time; Fertility. 


\section{Introduction}

The captive deer breeding industry has experienced an important period of growth worldwide within the past 40 years [1,2]. In recent years, there has been an increased trend toward deer farming in Spain, becoming a viable alternative to raising more conventional livestock species. In Spain, these are deer gaming farms where the main financial profits rely on antler trophies. Given that males have the highest economic value, the possibility of sex selection at breeding would represent significant management cost-savings and avoid the massive slaughter of females [3].

Presently, the most practical and effective methodology to predetermine the sex of progeny in livestock species is to perform sperm sex sorting by flow cytometry, which is based on the differences in DNA content between $\mathrm{X}$ and $\mathrm{Y}$ chromosome-bearing sperm [4]. This technique has been successfully applied in Sika deer (Cervus nipon) and red deer (Cervus elaphus), to produce offspring of the desired sex [5,6]. In the latter study, Anel-Lopez et al. [6] reported $50 \%$ fertility rates when using Y-bearing frozen-thawed sex-sorted sperm for artificial insemination (AI) in red deer. While this fertility rate is acceptable it is still far from the $75 \%$ reported when using conventional samples of frozen-thawed sperm. Surprisingly, in that study, post-thaw sperm evaluation parameters were not different between sorted and unsorted samples and hence could not account for the differences in fertility observed.

In this regard, the insemination timing is essential for pregnancy success, and depends on parameters such as the sperm and oocyte quality and lifespan, the time it takes for viable sperm to reach the place of fertilization and/or the timing of ovulation relative to insemination [7]. In our context, improving pregnancy rates by ascertaining the best time to perform the AI procedure would offer an economic incentive to overcome the perceived drawbacks associated with AI, including the additional expense associated with sperm sex-sorting and more intensive management. Because many of the factors affecting reproductive management protocols are species-specific, such protocols must be tailored to the species of interest [8]. Moreover, the sperm sex-sorting procedure accelerates several of the physiological sperm processes required 
for fertilization such as capacitation or acrosomal exocytosis, which in turn may decrease sperm longevity [9]. This emphasizes the need to improve sperm handling procedures prior to insemination.

Therefore, the aim of this study was to assess whether optimizing insemination timing protocols we could improve the fertility rates with frozen-thawed sex-sorted red deer sperm. For this, we compared the fertility results with 3 different types of sperm samples (Control sorted, Y-Sexed sperm and Conventional samples), when inseminated at different times following estrus synchronization.

\section{Materials \& Methods}

\subsection{Reagents and media}

All the reagents were purchase from Sigma-Aldrich (Madrid, Spain) unless otherwise indicated. The collecting medium used during sorting was a Tris-Citrate-Glucose (TCG) (pH: 7.3 and pOsm: $380 \mathrm{mOsm} / \mathrm{kg})$ containing: glucose $(250 \mathrm{mM})$, sodium citrate $(12 \mathrm{mM})$, EDTA (1.6 $\mathrm{mM})$, tris $(0.00033 \mathrm{mM})$, lactose $(5.1 \mathrm{mM})$, egg yolk $(\mathrm{EY})$ at $5 \%(\mathrm{~V} / \mathrm{V})$ penicillin $(0.7 \mathrm{mM})$, and streptomycin $(1.14 \mathrm{mM})$. The ejaculate washing medium was the transport extender with the addition of $2.5 \%(\mathrm{~V} / \mathrm{V})$ egg yolk. The transport medium was a Tris-Citrate-Fructose (TCF) (pH: 7.3 and pOsm: $330 \mathrm{mOsm} / \mathrm{kg}$ ) containing: Tris $(213 \mathrm{mM})$, citric acid monohydrate $(71.83$ $\mathrm{mM})$, fructose $(55.51 \mathrm{mM})$, egg yolk at $20 \%(\mathrm{~V} / \mathrm{V})$, penicillin $(0.7 \mathrm{mM})$, and streptomycin $(1.14$ $\mathrm{mM})$.

\subsection{Ejaculate collection and sperm sample preparation}

Samples were obtained from 8 mature stags during the breeding season (midSeptember). Animals were housed in a semi-free ranging regimen at Las Lomas Farm (Medianilla S.L., Cadiz, Spain). Animal handling and electroejaculation were performed in accordance with Spanish law in regards to the care and use of research animals (RD 53/2013) conforming to European Union regulation 2010/63. Semen collection by electroejaculation was carried out as described Anel-Lopez et al [10]. Briefly, males were anesthetized with 0.75 $\mathrm{mg} / \mathrm{Kg}$ of Xylazine (Rompun ${ }^{\circledR} 2 \%$; Bayer AG, Leverkusen, Germany). The rectum was cleared 
of feces and the prepucial area was shaved and washed with physiological saline solution. A

107 three-electrode probe (P.T. Electronics, Boring, OR, USA) connected to a power source that

108 allowed voltage and amperage control was used (P.T. Electronics). Probe diameter, probe length

109 and electrode length were 3.2, 35.0 and $6.6 \mathrm{~cm}$, respectively. The electroejaculation regimen

110 consisted of a consecutive series of 5 pulses of similar voltage applied for $5 \mathrm{~s}$ with $5 \mathrm{~s}$ of rest in

111 between each pulse. Initially, $1 \mathrm{~V}$ was applied that was then progressively increased at the next

112 series until reaching a maximum of $5 \mathrm{~V}$. Semen was collected by fractions in graduated glass

113 tubes. Then, fractions with urine contamination, that is, positive to Urea Test Strips (Diagnostic

114 Systems GmbH, Holzheim, Germany) were discarded. Fractions with total sperm motility under

$11580 \%$ were also discarded.

116 Semen was diluted 1:3 in TCG containing $2.5 \%$ egg yolk and then centrifuged at $600 \mathrm{xg}$

117 for $5 \mathrm{~min}$. The supernatant was removed and sperm concentration of the pellet was assessed

118 using a hemocytometer (Bürker chamber; Brand Gmbh, Wertheim, Germany), after diluting an

119 aliquot of the sample in a glutaraldehyde solution $(5 \mu \mathrm{L}$ of sample in $500 \mu \mathrm{L}$ of $2 \%$

120 glutaraldehyde solution $-29 \mathrm{~g} / \mathrm{L}$ glucose monohydrate, $10 \mathrm{~g} / \mathrm{L}$ sodium citrate tribasic dihydrate

121 and $2 \mathrm{~g} / \mathrm{L}$ sodium bicarbonate). Then, sperm aliquots were diluted to a concentration of $800 \mathrm{x}$

$12210^{6} \mathrm{sperm} / \mathrm{mL}$ in TCF medium supplemented with $20 \%(\mathrm{v} / \mathrm{v})$ of egg yolk and transported to the

123 sorting facility (about $8 \mathrm{~h}$ at $17^{\circ} \mathrm{C}$ ). Upon arrival to the laboratory each of the sperm samples

124 was split into 3 aliquots, to be processed to obtain: (1) conventional samples, following standard

125 freezing procedure for commercial purposes; (2) Control sorted samples, diluted and handled as

126 per sorted samples but without being submitted to the sorter passage; and, (3) Y Sex Sorted

127 (YSS) samples. Sperm samples for sorting (YSS) were further diluted to $100 \times 10^{6} \mathrm{sperm} / \mathrm{mL}$

128 with TCG (0\% egg yolk) medium and stained with $2.6 \mu \mathrm{L}$ of Hoechst-33342 (H-42) (Stock

129 solution: $25 \mathrm{mg} / \mathrm{mL}$ ) during $50 \mathrm{~min}$ at $34^{\circ} \mathrm{C}$ as previously described by Parrilla et al. [11].

$130 \quad$ 2.3. Flow cytometric sperm sex sorting

Just prior to sorting, stained sperm samples were filtered through a $30-\mu \mathrm{m}$ nylon mesh

132 filter. Then, $1 \mu \mathrm{L}$ of food dye $(0.002 \% \mathrm{w} / \mathrm{v}$; FD\&C \#40, Warner Jenkinson Company Inc., St.

133 Louis, MO, USA) was added to each sample to quench the fluorescence of H-42 in sperm with 
134 compromised cell membranes, allowing them to be gated out during the sorting process [20].

135 Sperm were sorted for YSS according to the Beltsville Sperm Sorting Technology method [21]

136 using a high-speed cell sorter (SX MoFlo, DakoCytomation Inc., Fort Collins, CO, USA)

137 modified for sperm sorting. The cell sorter was operated at $40 \mathrm{psi}$ and was equipped with a UV-

138 laser set at an output of $175 \mathrm{~mW}$ (Spectra Physics 1330, Mountain View, CA, USA). The

139 samples were sorted in the presence of a HEPES-buffer based sheath [22] supplemented with

$1400.1 \%$ EDTA (w/v), and were collected in $50-\mathrm{mL}$ tubes prefilled with $2.5 \mathrm{~mL}$ of collection

141 medium (TCG medium containing 5\% (v/v) of EY). A total of $20 \times 10^{6}$ sorted sperm was

142 collected per tube in an approximate volume of $25 \mathrm{~mL}$ with a purity of $\geq 90 \%$.

\subsection{Sperm cryopreservation}

Conventional samples were frozen at a concentration of $100 \times 10^{6} \mathrm{sperm} / \mathrm{mL}$ using Triladyl $^{\circledR}$ (Minitüb, Tiefenbach, Germany), supplemented with 20\% (v/v) EY, following the

147 manufacturer's instructions. Sorted sperm were centrifuged at $3000 \mathrm{xg}$ for $4 \mathrm{~min}$ at $21^{\circ} \mathrm{C}$. The 148 supernatant was discarded and the pellets were re-extended to $40 \times 10^{6} \mathrm{sperm} / \mathrm{mL}$ using 149 Triladyl $^{\circledR}$ supplemented with $20 \%(\mathrm{v} / \mathrm{v})$ of EY. Then sperm samples were immersed in a programmable temperature-controlled water bath (Programmable Model 9612, PolyScience, Niles, IL, USA) and slowly cooled from $21^{\circ} \mathrm{C}$ to $5{ }^{\circ} \mathrm{C}$ for over $90 \mathrm{~min}$, and left for an equilibration time of $2 \mathrm{~h}$. After this time-period, processed samples were packaged in $0.25 \mathrm{~mL}$ straws (Minitüb, Tiefenbach, Germany), placed on a rack $4 \mathrm{~cm}$ above liquid nitrogen for 10

154 min, and then plunged into liquid nitrogen and stored accordingly. but without being submitted to the sorter passage. For this purpose, control sorted sperm were centrifuged to remove the supernatant and then gradually diluted to $20 \times 10^{6}$ sperm $/ \mathrm{mL}$ using HEPES-buffer based sheath fluid in the presence of collection medium. Then control sperm samples were stored at room temperature $\left(21-22^{\circ} \mathrm{C}\right)$ for approximately $4 \mathrm{~h}$ mimicking the conditions to which sorted sperm were exposed. Freezing of control sorted samples was performed concomitantly and following the exact same protocol as per sorted samples (YSS). 


\subsection{Artificial insemination}

The trial was conducted at the Medianilla farm in Cádiz (Spain) during September of 2013, 2014 and 2015. Six hundred thirty-four Iberian deer (4-6 years old; 75-101 kg body weight) housed in outdoor enclosures that provide exposure to natural fluctuations in light and temperature were inseminated. Estrous synchronization of hinds was performed as previously described by Garde et al. [1]. Briefly, single controlled internal drug release (CIDR) devices (type G, 330 mg progesterone per device, InterAg Effective Agricultural System, Hamilton, NZ) were inserted vaginally. Then CIDRs were replaced in each animal on day 9 to ensure high progesterone concentrations and at this time we administered $0.75 \mathrm{~mL}$ of $\mathrm{PGf}_{2} \alpha$ (IM;

172 Prosolvin $^{\circledR}$; VIRBAC S.A, Cataluña, SPAIN) per hind. Upon CIDR removal on day 12 (3 days 173 following $\mathrm{PgF} 2 \alpha$ administration), hinds were given $250 \mathrm{IU}$ of eCG (Folligon ${ }^{\circledR}$, Intervet, 174 Salamanca, Spain) intramuscularly. One straw per hind was used to carry out the AI. Females were then randomly inseminated transcervically with Control sorted sperm (158 hinds) and Ysexed sperm (239 hinds) at a concentration of $40 \times 10^{6} \mathrm{sperm} / \mathrm{mL}$ or Conventional frozenthawed sperm (237 hinds) at a concentration of $100 \times 10^{6} \mathrm{sperm} / \mathrm{mL}$. At the time of

178 insemination, hinds were individually identified and the exact time after eCG administration 179 was recorded. Hence timing of insemination was divided into 4 intervals, corresponding to hours post-eCG administration: I_1, 55:01 - 55:30 h; I_2, 55:31 - 56:00 h; I_3, 56:01 - 56:30 h; and, I_4, 56:31 - 57:00 h. Inseminated hinds were kept in groups until approximately 1 week before the due date, at which time they were moved to individual pens for better monitoring. Fertility rates were assessed upon delivery rates. The sex of fawns was recorded at birth.

\subsection{Statistical analysis}

Data were analysed using the SAS ${ }^{\mathrm{TM}}$ v.9.1. Package (SAS Institute Inc., Cary, NC, USA). Sperm fertility data were compared using a LOGISTIC procedure considering a binary response model. The statistical model included sperm sample (Control sorted; YSS; Conventional) and time of insemination (I_1, I_2, I_3 or I_4) as factor, and fertility rates as a 
response variable. Between-group differences in the frequency were tested using Wald ChiSquare. Results are presented as percentages. Significance level was set at $\mathrm{P}<0.05$.

\section{Results}

Overall fertility rates were similar $(\mathrm{P}>0.05)$ between YSS samples $(49.8 \%)$ and Control sorted samples (51.3\%) (Figure 1). Conversely, Conventional sperm samples yielded higher $(\mathrm{p}<0.05)$ fertility rates $(77.6 \%)$ when compared to both Sexed and Control sorted samples (Figure 1).

There were no differences in pregnancy rates in Control sexed samples among the different insemination intervals (Table 1a). Conversely, for YSS samples there were remarkable differences $(\mathrm{P}<0.05)$ among insemination intervals (Table $1 \mathrm{~b})$. For instance, both I_1 and I_2 yielded the highest pregnancy rates ( 80 and $83.1 \%$, respectively) within the sperm type group. However, I_3 and I_4 yielded the lowest pregnancy rates (33.3 and 3.3\%, respectively) $(\mathrm{P}<0.05)$ (Table 1b). In fact, pregnancy rates for YSS sperm used in intervals I_1 and I_2 were similar $(\mathrm{P}>0.05)$ to the average pregnancy rates obtained with Conventional samples $(77.6 \%)$ (Table 1c). Within Conventional samples, there were also differences in pregnancy rates according to the insemination interval. In fact, I_3 yielded the highest pregnancy rates (91.7\%; $\mathrm{P}<0.05)$ within the group, while $\mathrm{I} \_1$ yielded the lowest pregnancy rates $(66.7 \%$; $\mathrm{P}<0.05)$. Results were intermediate for I_2 and I_4 (Table 1c).

As expected, the males were accounted for $56.8 \%$ and $57 \%$ of the offspring for both Control sexed samples and Conventional samples, respectively. Conversely, $94 \%$ of the offspring were males when using YSS samples $(\mathrm{P}<0.05)$ (Figure 2).

\section{Discussion}

Sperm sex-sorting by flow cytometry is currently the best technology available to modify the offspring sex-ratio in livestock species, thus allowing for faster genetic progress and increased production while reducing wastage. However, fertility rates obtained after AI with sexed samples are lower than those obtained with unsorted samples under the same management 
conditions in all species studied $[6,12,13]$. This is no different for red deer, a species in which

219 the main economic incentive relies on producing trophy males for hunting events $[1,14]$. The reasons behind the lower fertility observed with sex-sorted sperm are not entirely clear. Both factors related to sperm handling during the sorting process and to female breeding management may account for the reduced fertility of sex-sorted sperm $[15,16]$. While this is sometimes attributed to low sperm yields and the use of lower insemination dosages, increasing the number of sperm to reach a concentration comparable to those used with non-sexed sperm did not improve pregnancy rates in heifers [17]. This may be due partially to the fact that the sorting process is not innocuous, given that sperm are exposed to many stressors such as fluorescent dyes, high dilution rates, mechanical injuries, laser illumination and a subsequent passage through an electric field [18]. Moreover, the sex-sorting process may induce capacitation-like changes in sperm from several species, including ram and boar [19]. The development of species-specific protocols in regards to sperm handling and insemination timing may help overcome to some degree the decreased pregnancy rates observed with sexed-sorted sperm. cytometry is an excellent technology for Y-sperm separation when applied to a red deer sperm production system [6,10]. Hence, in this study the male:female offspring sex ratio was 94:6 for hinds inseminated with Y sex-sorted sperm, similar to a previous study [6]. However, overall fertility rates were lower for sorted than conventional samples. In our previous study [6], that

237 fertility reduction could not be attributed to sperm quality parameters which were comparable among the different treatments. Based upon these results, we decided to evaluate the effect of insemination timing following induction of ovulation on pregnancy rates. Interestingly, within Y-sorted sperm samples, pregnancy rates were significantly higher when hinds were inseminated in the interval spanning 55:01 to 56:00 h following eCG administration. However, pregnancy rates plummeted when sorted sperm was inseminated at later intervals. With the exception of a peak in pregnancy rates for Conventional samples inseminated in the interval

244 spanning 56:01-56:30 h following eCG administration, differences among the other intervals 
246 for control sorted samples. Overall these results underscore the importance of devising species-

247 specific protocols in regards to breeding management when using sex-sorted sperm samples. In

248 addition these results are in concordance with our previous work [6] where the in vitro sperm

249 quality of sex-sorted samples was even higher than that for the control samples. Interestingly,

250 insemination of sex-sorted sperm during intervals presumably closer to ovulation yielded

251 pregnancy rates that were not different to the average rates obtained with Conventional samples.

252 While this further supports the importance of insemination timing, the fact that the sex-sorting

253 process also selects viable sperm may also partially account for the remarkable pregnancy rates

254 obtained when inseminating closer to ovulation induction [10] and to the differences observed

255 with the control-sorted sperm, where such selection is not performed.

256

Notably, it has been suggested that the lower number of sperm used when inseminating

with sex-sorted sperm may be a major factor negatively impacting pregnancy rates in several species, including cows [20], horse [21], sheep [22] or red deer [6]. However, we believe that our work argues against this hypothesis. When inseminated at the optimal time, the pregnancy rates obtained with 10 million Y sex-sorted sperm were higher than the average pregnancy rates obtained with 25 million of Conventional sperm. Thus, adjusting the insemination timing is especially important with sex-sorted semen given a lower insemination dose [23] and a shorter life-span or at least a shorter period of fertilizing capacity of sperm within the female reproductive tract [24]. Garner et al. [18] hypothesized that the increased precision of the time of ovulation and of insemination relative to ovulation may play a critical role in obtaining satisfactory results in fertility because of this fact. In this way, our results confirm that hypothesis. For instance, Lu et al. [25] in bull or Maxwell et al. [24] in ram spermreported that the sorting process induces sperm precapacitation changes. In the same way, Hollinshead et al. [26] concluded that the sorting and freezing-thawing process accelerate the maturation of sorted-frozen-thawed ram sperm, decreasing their fertilizing lifespan. This would reduce sorted

271 sperm longevity and account for the reduced pregnancy rates observed not only in deer [6] but 272 also in other species, like cattle [27]. Because of this previews and higher maturation, for use in 273 AI, insemination close to the site of fertilization and time of ovulation is critical for a successful 
274 fertilization and ongoing pregnancy. In the opposite, in cattle pregnancy rates are higher when

275 insemination is carried out around 60h rather than $36 \mathrm{~h}$ following CIDR removal [28].

276 Interestingly, in our study, highest pregnancy rates with sorted sperm were obtained at around

$27755-56 \mathrm{~h}$ following eCG administration. It is possible that the fertility window in red deer is

278 smaller than that reported in other species, in addition to other factors possibly affecting fertility

279 in a wild species such as handling stress. Other studies in red deer with unsorted frozen-thawed

280 sperm reported the best intervals to be between 48 and $55 \mathrm{~h}$ after CIDR removal [29] or between

28150 and $62 \mathrm{~h} \mathrm{[30],} \mathrm{which} \mathrm{would} \mathrm{be} \mathrm{around} \mathrm{the} \mathrm{most} \mathrm{fertile} \mathrm{period} \mathrm{identified} \mathrm{herein.}$

282

In summary, from our results we infer the following: 1) sex-sorted red deer sperm are

283

284

285

286

287

288

289

290

291

292

293

294

295

296

297

298

299

300

301

302

303

304

305

viable for a short time span once inseminated, which may explain that the best results are obtained at a time likely closer to ovulation; and, 2) stressors related to female handling for insemination may further alter the ability of sorted sperm to fertilize the oocyte because of their precapacitated status. Additional studies in regards to sperm and oocyte physiology in red deer may further clarify our findings.

\section{Founding}

This work was supported by Spanish Ministry of Economy and Competitiveness (AGL201021487 and IPT-2012-1066-060000).

\section{Bibliography}

[1] Garde JJ, Martínez-Pastor F, Gomendio M, Malo a. F, Soler a. J, Fernández-Santos MR, et al. The application of reproductive technologies to natural populations of red deer. Reprod Domest Anim 2006;41:93-102. doi:10.1111/j.1439-0531.2006.00773.x.

[2] Kjelland ME, González-Marín C, Gosálvez J, López-Fernández C, Lenz RW, Evans $\mathrm{KM}$, et al. DNA fragmentation kinetics and postthaw motility of flow cytometric-sorted white-tailed deer sperm. J Anim Sci 2011;89:3996-4006. doi:10.2527/jas.2011-4014.

[3] Gao QH, Wang HE, Zeng WB, Wei HJ, Han CM, Du HZ, et al. Embryo transfer and sex determination following superovulated hinds inseminated with frozen-thawed sex-sorted Y sperm or unsorted semen in Wapiti (Cervus elaphus songaricus). Anim Reprod Sci 2011;126:245-50. doi:10.1016/j.anireprosci.2011.05.006.

[4] Rath D, Johnson LA. Application and commercialization of flow cytometrically sexsorted semen. Reprod Domest Anim 2008;43 Suppl 2:338-46. doi:10.1111/j.1439- 
[5] Gao QH, Wei HJ, Han CM, Du HZ, Zhang ZG, Zhao WG, et al. Successful low dose insemination of flow cytometrically sorted Sika (Cervus nippon) sperm in Wapiti (Cervus elaphus). Anim Reprod Sci 2010;118:89-93.

[6] Anel-López L, García-Álvarez O, Parrilla I, Del Olmo D, Maroto-Morales A,
Fernandez-Santos MRR, et al. Effect of sex-sorting and cryopreservation on the postthaw sperm quality of Iberian red deer spermatozoa. Theriogenology 2017;89:206-13. doi:10.1016/j.theriogenology.2016.11.010.

[8] Seidel GE. Assisted Reproduction in Horses: What Can Be Learned from Assisted
Reproduction in Cattle? J Equine Vet Sci 2012;32:372-5.

[7] Nebel R., Dransfield M., Jobst S., Bame J. Automated electronic systems for the detection of oestrus and timing of AI in cattle. Anim Reprod Sci 2000;60-61:713-23. doi:10.1016/S0378-4320(00)00090-7. doi:10.1016/j.jevs.2012.05.006.

[9] Mocé E, Graham JK, Schenk JL. Effect of sex-sorting on the ability of fresh and cryopreserved bull sperm to undergo an acrosome reaction. Theriogenology 2006;66:929-36. doi:10.1016/j.theriogenology.2006.01.063.

[10] Anel-López L, García-Álvarez O, Parrilla I, Del Olmo D, Fernández-Santos MR, Soler AJ, et al. The Effect of Oxidative Stress on Thawed Bulk-Sorted Red Deer Sperm. Reprod Domest Anim 2016:1-8. doi:10.1111/rda.12694.

[11] Parrilla I, Vázquez JM, Cuello C, Gil MA, Roca J, Di Berardino D, et al. Hoechst 33342 stain and u.v. laser exposure do not induce genotoxic effects in flow-sorted boar spermatozoa. Reproduction 2004;128:615-21. doi:10.1530/rep.1.00288.

[12] Hollinshead FK, Evans G, Evans KM, Catt SL, Maxwell WM, O'Brien JK. Birth of lambs of a pre-determined sex after in vitro production of embryos using frozen-thawed sex-sorted and re-frozen-thawed ram spermatozoa. Reproduction 2004;127:557-68.

[13] Lindsey AC, Bruemmer JE, Squires EL. Low dose insemination of mares using nonsorted and sex-sorted sperm. Anim Reprod Sci 2001;68:279-89. doi:10.1016/S03784320(01)00165-8.

[14] Kruuk LEB, Slate J, Pemberton JM, Brotherstone S, Guinness F, Clutton-Brock T. Antler size in red deer: heritability and selection but no evolution. Evolution (N Y) 2002;56:1683-95.

[15] Seidel GE, Schenk JL. Pregnancy rates in cattle with cryopreserved sexed sperm: Effects of sperm numbers per inseminate and site of sperm deposition. Anim Reprod Sci 2008;105:129-38. doi:10.1016/j.anireprosci.2007.11.015.

[16] Suh TK, Schenk JL, Seidel GE. High pressure flow cytometric sorting damages sperm. Theriogenology 2005;64:1035-48. doi:10.1016/j.theriogenology.2005.02.002.

[17] Dejarnette JMM, Leach MAA, Nebel RLL, Marshall CEE, McCleary CRR, Moreno JFF. Effects of sex-sorting and sperm dosage on conception rates of Holstein heifers: is comparable fertility of sex-sorted and conventional semen plausible? J Dairy Sci 2011;94:3477-83. doi:10.3168/jds.2011-4214.

[18] Garner DL. Flow cytometric sexing of mammalian sperm. Theriogenology 2006;65:943- 
[19] Catt S, O’Brien J, Maxwell W, Evans G. Assessment of Ram and Boar Spermatozoa during Cell-sorting by Flow Cytometry. Reprod Domest Anim 1997;32:251-8. doi:10.1111/j.1439-0531.1997.tb01290.x.

[20] Seidel GE, Schenk JL, Herickhoff LA, Doyle SP, Brink Z, Green RD, et al. Insemination of heifers with sexed sperm. Theriogenology 1999;52:1407-20. doi:10.1016/S0093691X(99)00226-5.

[21] Lindsey AC, Morris LHA, Allen WR, Chenk JL, Squires EL, Bruemmer JE. Hysteroscopic insemination of mares with low numbers of nonsorted or flow sorted spermatozoa. Equine Vet J 2010;34:128-32. doi:10.2746/042516402776767178.

[22] Hollinshead FK, O'Brien JK, Maxwell WMC, Evans G. Production of lambs of predetermined sex after the insemination of ewes with low numbers of frozen-thawed sorted X- or Y-chromosome-bearing spermatozoa. Reprod Fertil Dev 2002;14:503-8.

[25] Lu K., Seidel G. Effects of heparin and sperm concentration on cleavage and blastocyst development rates of bovine oocytes inseminated with flow cytometrically-sorted sperm. Theriogenology 2004;62:819-30. doi:10.1016/j.theriogenology.2003.12.029.

[26] Hollinshead F., O’Brien J., Gillan L, Meyers M, Maxwell WM., Evans G. Liquid storage of flow cytometrically sorted ram spermatozoa. Theriogenology 2004;62:587-605. doi:10.1016/J.THERIOGENOLOGY.2003.11.020.

[27] Pellegrino CAG, Morotti F, Untura RM, Pontes JHF, Pellegrino MFO, Campolina JP, et al. Use of sexed sorted semen for fixed-time artificial insemination or fixed-time embryo transfer of in vitro-produced embryos in cattle. Theriogenology 2016;86:888-93.

[28] Richardson BN, Larimore EL, Walker JA, Utt MD, Dejarnette JM, Perry GA. Comparison of fertility of liquid or frozen semen when varying the interval from CIDR removal to insemination. Anim Reprod Sci 2017;178:61-6. doi:10.1016/j.anireprosci.2017.01.010.

[29] Aller JF, Fernandez O, Sanchez E. Fixed-time artificial insemination in red deer (Cervus elaphus) in Argentina. vol. 115. 2009. doi:10.1016/j.anireprosci.2008.11.018.

[30] Mcmillan WH, Asher GW. Development of large scale commercial AI for genetic improvement in farmed red deer in New Zealand. Proc New Zeal Soc Anim Prod 2007;67:82-90. 
REVISED

$388 \quad$ Figure Legends

389 Figure 1:

390 Fertility rates in red deer hinds inseminated (Control sexed $n=158$; YSS $n=259$; Conventional

391 Samples $n=237$ ) with sex-sorted frozen-thawed stag semen. One straw per hind was used to

392 carry out the artificial insemination. Sperm treatments included: Control sexed sperm (at a

393 concentration of $40 \times 10^{6}$ sperm $/ \mathrm{mL}$ ), Y-sorted sperm (YSS; at a concentration of $40 \times 10^{6}$

394 sperm $/ \mathrm{mL}$ ) and Conventional samples (at a concentration of $100 \times 10^{6}$ sperm $/ \mathrm{mL}$ ). Pregnancy

395 rates were calculated based upon birth rates. Different textures show differences $(\mathrm{P}<0.05)$

396 among treatments.

397

398 Figure 2:

399 Sex ratio resulting from insemination of Y-sexed or control sperm from red deer. Sperm 400 treatments included: Control sexed sperm (at a concentration of $40 \times 10^{6} \mathrm{sperm} / \mathrm{mL}$ ), Y-sorted 401 sperm (YSS; at a concentration of $40 \times 10^{6} \mathrm{sperm} / \mathrm{mL}$ ) and Conventional samples (at a 402 concentration of $100 \times 10^{6}$ sperm $\left./ \mathrm{mL}\right)$. Different textures show differences $(\mathrm{P}<0.05)$ among 403 treatments.

404

405 
406 Table 1: Pregnancy rates for each insemination interval following CIDR removal for hinds 407 inseminated with Control sexed, Y sorted or Conventional frozen-thawed stag sperm from red 408 deer. Insemination intervals following eCG administration were set as follows: I_1 55:01 $40955: 30$ h, I_2 55:31 - 56:00 h, I_3 56:01 - 56:30 h, I_4 56:31 - 57:00 h. Sperm treatments 410 included: Control sexed sperm (at a concentration of $40 \times 10^{6} \mathrm{sperm} / \mathrm{mL}$ ), Y-sorted sperm (YSS; 411 at a concentration of $40 \times 10^{6} \mathrm{sperm} / \mathrm{mL}$ ) and Conventional samples (at a concentration of 100 $412 \mathrm{x} 10^{6} \mathrm{sperm} / \mathrm{mL}$ ). Pregnancy rates were calculated based on birth rates. Different capital letters 413 within sperm treatment denote significant differences $(\mathrm{P}<0.05)$ among insemination intervals.

$414 \quad 1 a$

415

\begin{tabular}{|c|c|c|c|c|}
\hline \multicolumn{5}{|c|}{ Control Sexed } \\
\cline { 1 - 4 } Interval & Pregnant hinds & Total hinds & Fertility & Differences \\
\hline I_1 & 21 & 39 & $53,8 \%$ & A \\
\hline I_2 & 20 & 40 & $50,0 \%$ & A \\
\hline I_3 & 22 & 38 & $57,9 \%$ & A \\
\hline I_4 & 18 & 41 & $43,9 \%$ & A \\
\hline Total & 81 & 158 & $51,3 \%$ & \multirow{2}{*}{} \\
\cline { 1 - 3 } & & &
\end{tabular}

$416 \quad 1 b$

417

\begin{tabular}{|c|c|c|c|c|}
\hline \multicolumn{5}{|c|}{ YSS } \\
\cline { 1 - 4 } Interval & Pregnant hinds & Total hinds & Fertility & Differences \\
\hline I_1 & 48 & 60 & $80,0 \%$ & A \\
\hline I_2 & 49 & 59 & $83,1 \%$ & A \\
\hline I_3 & 20 & 60 & $33,3 \%$ & B \\
\hline I_4 & 2 & 60 & $3,3 \%$ & C \\
\hline Total & 119 & 239 & $49,8 \%$ & \multicolumn{1}{|c}{} \\
\cline { 1 - 3 } & \multicolumn{3}{|c}{}
\end{tabular}

418

$1 c$

\begin{tabular}{|c|c|c|c|c|}
\hline \multicolumn{5}{|c|}{ Conventional Samples } \\
\cline { 1 - 4 } Interval & Pregnant hinds & Total hinds & Fertility & Differences \\
\hline I_1 & 40 & 60 & $66,7 \%$ & A \\
\hline I_2 & 45 & 59 & $76,3 \%$ & B \\
\hline I_3 & 55 & 60 & $91,7 \%$ & C \\
\hline I_4 & 44 & 58 & $75,9 \%$ & B \\
\cline { 1 - 4 } Total & 184 & 237 & $77,6 \%$ & \multirow{2}{*}{} \\
\cline { 1 - 3 } & & &
\end{tabular}


REVISED

$421 \quad$ Figure 1.

422

423

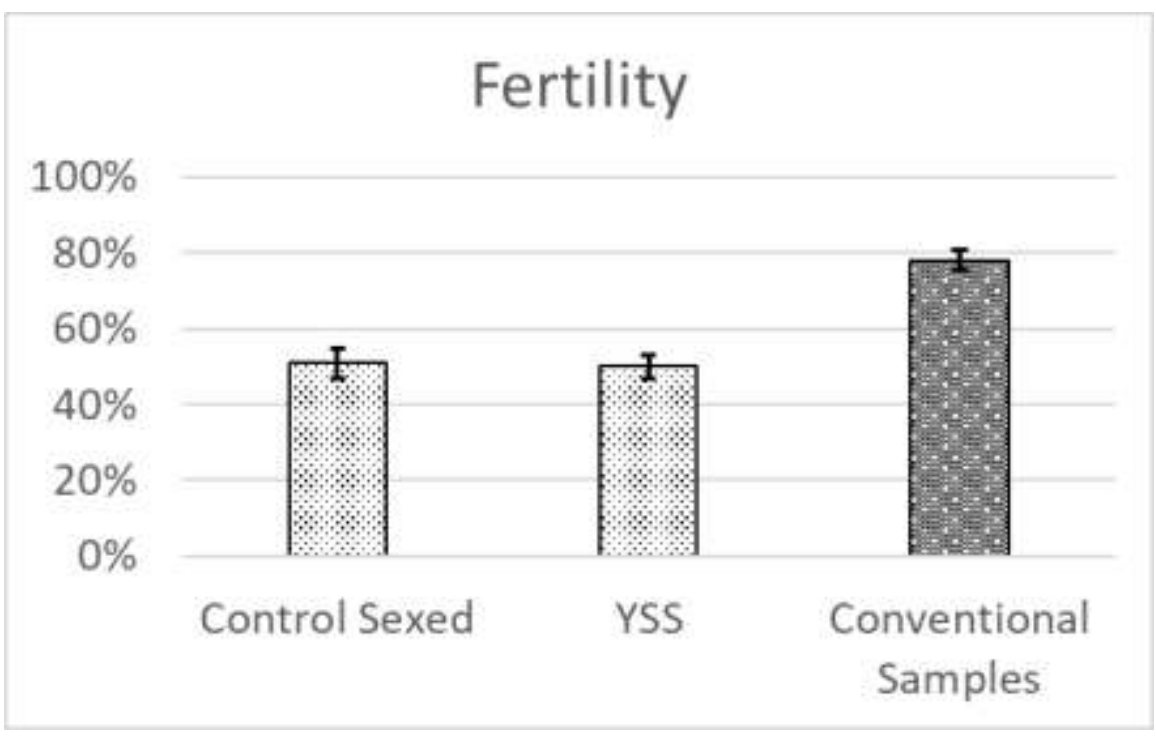

424

425

426

427 Figure $1 \mathrm{~b}$.

428

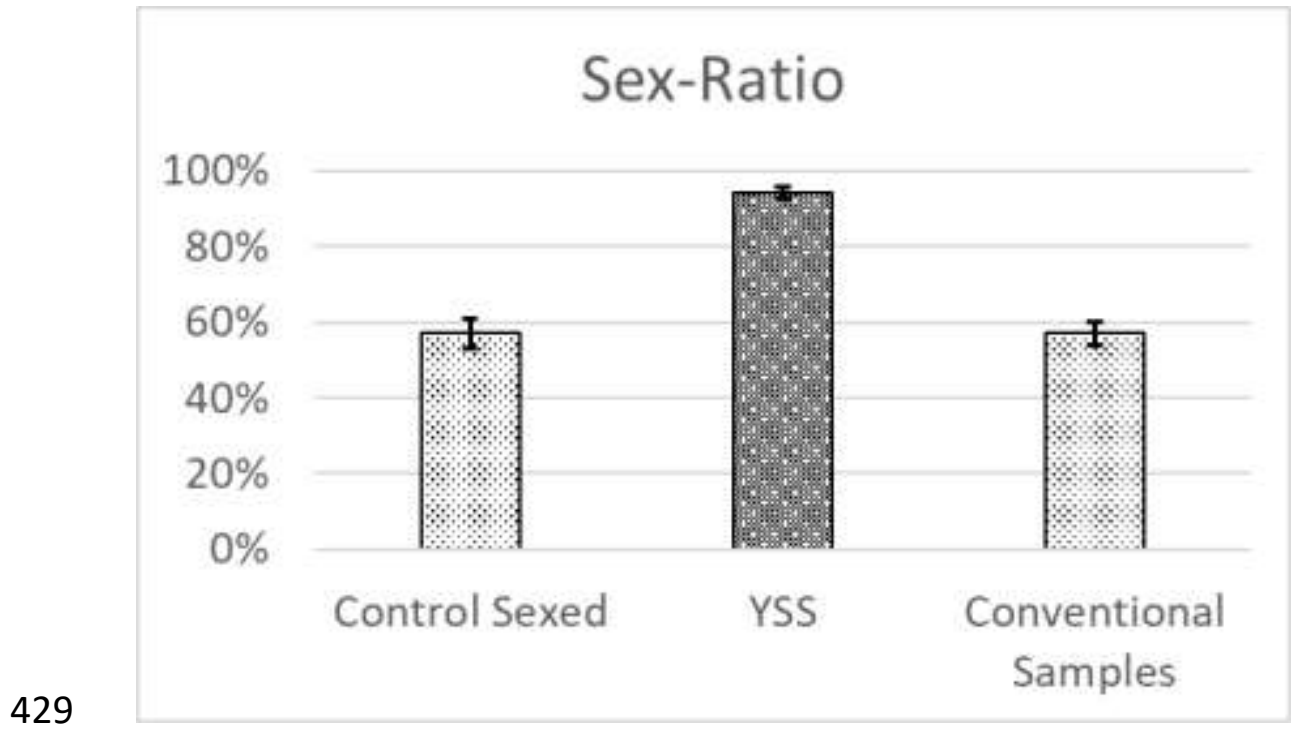

